\title{
DIGITALCOMMONS
}

—@WAYNESTATE-

Wayne State University

$4-1-2012$

\section{The Report of the Military Leadership Diversity Commission: An Inadequate Basis for Lifting the Exclusion of Women from Direct Ground Combat}

Kingsley R. Browne

Wayne State University

\section{Recommended Citation}

Kingsley R. Browne, The Report of the Military Leadership Diversity Commission: An Inadequate Basis for Lifting the Exclusion of Women from Direct Ground Combat, SSRN, Sept. 25, 2012, https://papers.ssrn.com/sol3/papers.cfm?abstract_id=2151965

Available at: https://digitalcommons.wayne.edu/lawfrp/266 


\title{
The Report of the Military Leadership Diversity Commission:
}

An Inadequate Basis for Lifting the Exclusion of

Women from Direct Ground Combat

\author{
Kingsley R. Browne ${ }^{1}$ \\ Wayne State University Law School
}

April 2012

\footnotetext{
1 Professor, Wayne State University Law School, Detroit, MI 48202. kingsley.browne@wayne.edu
} 
This page intentionally left blank 


\section{Summary}

The recommendation of the Military Leadership Diversity Commission to lift the exclusion of women from ground combat is deeply irresponsible and cannot be taken seriously. The Commission's lodestar was diversity, not military effectiveness, and it failed to take into consideration a wealth of information bearing on its recommendation.

The Commission's recommendation was based primarily on its analysis of three sources of information: a 1997 RAND study by Harrell \& Miller, a 2009 report of the Defense Advisory Committee on Women in the Services, and anecdotal reports. None of the sources that the Commission consulted can be considered authoritative, and the Commission's analysis of the sources that it did consult was superficial and in conflict with some of the facts, as opposed to the "spin," contained in these very sources.

The Commission substantially downplayed the sex difference in strength and other physical capacities, striking down the straw man that "all women lack the physical ability to perform in combat roles," but never addressing how many women there are who actually possess that ability, a piece of data that is highly relevant to its recommendation. A British Ministry of Defence study concluded that the number was about one percent of trained female soldiers, but the Commission did not consult that source, preferring to deal with straw arguments that no one actually makes.

The MLDC report does not mention the word "pregnancy," despite the fact that there is much data to suggest that pregnancy has substantial adverse effects on deployability and readiness. Importing these problems into ground combat units is exceedingly unwise, but the Commission chose to ignore the entire issue.

Finally, the Commission reported that there was "little evidence" that integration of women has had a negative impact on cohesion and performance. In fact, there is such evidence, including that presented in the sources that the Commission did consult-the RAND report, the DACOWITS report, and in anecdotal accounts. Moreover, on this issue, as on others, the Commission's response to what it viewed as an absence of evidence was not 
to call for the gathering of evidence but rather to declare that there was no problem.

In fact, the very sources cited by the Commission provide substantial reason to question its conclusions. Although the DACOWITS report downplayed any concerns about integration, it actually contained information suggesting that some members of its focus groups entertained substantial concerns that integration would negatively affect cohesion. Reasons cited included sexual tension and harassment, female emotionality, having to exercise discretion or decorum to avoid offending females, differential physical standards, the impact on personnel strength caused by women getting pregnant (often deliberately) and either not deploying or being sent home as a consequence, as well as logistical issues such as hygiene. The RAND report cited similar concerns.

The Commission did not take seriously the objections of those who counsel caution. When it mentioned these objections at all, the source of the objection was never mentioned, the specific arguments never dealt with, and, in fact, when any source was cited at all, it was to descriptions of the arguments against integration by proponents of integration. From the bibliography of the Commission report, one would not know that anyone had ever written anything negative about the sexual integration of combat units.

If the question of integration of ground combat units is to be considered, it should be based on an analysis produced by people whose expertise is combat, not diversity. Moreover, in considering whether to make such a momentous decision, the opinions of the people most affected by the decision and in the best position to estimate its effects-men in ground-combat specialties with recent ground-combat experience-should be solicited and taken seriously. 


\section{The Report of the Military Leadership Diversity Commission: An Inadequate Basis for Lifting the Exclusion of Women from Direct Ground Combat}

\section{Introduction}

The National Defense Authorization Act for Fiscal Year 2009 authorized creation of the Military Leadership Diversity Commission (MLDC). The Commission was charged with conducting "a comprehensive evaluation and assessment of policies that provide opportunities for the promotion and advancement of minority members of the Armed Forces, including minority members who are senior officers," and it was directed to report to the President and Congress on its recommendations "for improving diversity within the Armed Forces.” In March 2011, the Commission issued its report, From Representation to Inclusion: Diversity Leadership for the $21^{\text {st }}$-Century Military. That report made a number of recommendations, including a recommendation that all restrictions on women serving in combat roles be lifted. Although the Commission suggested that the modification should be "time-phased," it stated that any delay in developing new policies was for purposes of determining how integration should proceed, not whether it should proceed. ${ }^{1}$

Elimination of age-old restrictions barring women from combat is a serious step that should be taken only with a high degree of confidence that it would not degrade the military's capacity to perform its mission. Unfortunately, the MLDC failed to give the question the serious attention it deserved. The Commission's failure to focus clearly on combat effectiveness is understandable in light of its charter, which was directed toward diversity and not toward military effectiveness. Had its charge been to study battlefield effectiveness and to suggest means by which to enhance it, the composition of the Commission would have been very different-putting a premium on combat experience rather than diversity experience-and the Commission

\footnotetext{
1 Military Leadership Diversity Commission. (2011). From Representation to Inclusion: Diversity Leadership for the 21st-Century Military, p. 74.

http://mldc.whs.mil/download/documents/Final Report/MLDC_Final_Report.pdf.
} 


\section{Kingsley R. Browne}

would have had to collect and examine a very different kind of data. If a "Battlefield Effectiveness Commission" were to reach the same conclusions as the MLDC actually did, one can only imagine that it would have done a better job of justifying them.

Presumably because of its dedication to diversity, the Commission appeared to believe that the burden of proof rests on those favoring current policies that exclude women from ground combat rather than on those who advocate a radical change in the status quo. For example, the Commission reports that there is "little evidence" that inclusion of women in previously closed fields has had negative effects on performance or cohesion. Note that the Commission does not suggest that there is much evidence that it would not have negative effects. Even aside from the fact that the Commission ignored a great deal of evidence of negative effects despite its airy claim that its report was "founded on rigorous research," the Commission should have sought more information before concluding that integration does not present serious threats to cohesion and recommending a dramatic change in policy.

Strangely, the principal MLDC report did not make even passing reference to the 1992 report of the Presidential Commission on the Assignment of Women in the Armed Forces, ${ }^{3}$ which had, in the wake of the Gulf War, recommended against admission of women into ground-combat specialties. ${ }^{4}$ On the burden of proof issue, noted military sociologist and member of the Presidential Commission Charles Moskos stated at that time:

You raised a question, Mr. Chair, where the burden of proof should lie. Other things being equal, you say, well, then let equal opportunity triumph. Well, most of the evidence that we've heard here-and there will be some debate about the degree-is that mixed-gender units,

2 MLDC Report, p. viii.

3 Presidential Commission on the Assignment of Women in the Armed Forces. (1992). Women in Combat: Report to the President. McLean, VA: Brassey’s (US).

4 The Presidential Commission Report was mentioned once in Decision Paper \#2 for the unsurprising proposition that "male servicemenbers are on average physically stronger and have higher cardiovascular abilities.” Military Leadership Diversity Commission. (2011). Decision Paper \#2: Branching and Assignments, p. 30, note 33. 
particularly as it gets closer to the combat area, have lower deployment rates, higher attrition, less physical strength, more sexual activity, higher costs, et cetera, et cetera. It would seem to me the burden of the proof would be on the side of saying equal opportunity is of such significance that we're going to override some of these costs. $^{5}$

Dr. Moskos’s observations are no less apt today.

Despite the MLDC's claim that its recommendations are based on "rigorous research," the data sources it relied upon are wholly inadequate to the task and provide no basis for its conclusion that "neither research nor practical experience" supports concern over negative effects of sexual integration. Indeed, some of the sources cited by the Commission contain information inconsistent with its conclusions, while others lack any kind of authoritative basis at all. It is quite remarkable that the Commission would reach its conclusion based on such a perfunctory inquiry, giving great weight to sources of questionable merit and ignoring abundant evidence to the contrary.

Section I of this paper will describe the sources relied upon by the Commission and will attempt to demonstrate that the sources are not as authoritative as the Commission appeared to believe; moreover, these sources themselves provide data inconsistent with the Commission's conclusions. Section II of this paper will show that there is much available information touching on relevant subjects that does not appear even to have been consulted by the Commission. Finally, Section III will note a series of issues that the Commission did not even touch on that should be weighed in any decision to integrate women into combat units.

$5 \quad$ Presidential Commission, p. 47. 
Kingsley R. Browne

\section{THE COMMISSION'S PRIMARY SOURCES OF DATA PROVIDE LITTLE SUPPORT FOR ITS CONCLUSIONS OR RECOMMENDATIONS}

The Commission relied primarily on three sources in reaching its conclusion that there was no cause for concern that sexual integration would negatively effect cohesion or effectiveness: a 1997 RAND report on sexual integration, a 2009 report of the Defense Advisory Committee on Women in the Services (DACOWITS), and anecdotal evidence. Taken together they are very weak support for the Commission's recommendations.

\section{A. The 1997 Harrell and Miller Study}

The MLDC placed primary weight on the 1997 RAND Corporation report titled New Opportunities for Military Women: Effects Upon Readiness, Cohesion, and Morale authored by Margaret Harrell \& Laura Miller. That report concluded that "gender integration is perceived to have a relatively small effect on readiness, cohesion, and morale in the units we studied." ${ }^{6}$ It should be emphasized that the RAND report did acknowledge that there were some negative effects. It was able to characterize those effects as small, however, only by attributing many of the adverse consequences that it reported to "other influences, such as leadership and training."7 As discussed below, however, it took substantial intellectual gymnastics by Harrell and Miller to divorce these consequences from integration itself.

A thorough review of the RAND study would have revealed good reason for a responsible decision-maker in the MLDC's position to make further inquiry. For example, Harrell and Miller found considerable resentment among men due to their perception that despite demands for equal recognition women do not contribute their share to the work of the unit. ${ }^{8}$ They also found that dating and sexual relationships were perceived to

6 Harrell, M. C., \& Miller, L. L. (1997). New Opportunities for Military Women: Effects Upon Readiness, Cohesion, and Morale. Santa Monica, CA: RAND, p. 99.

7 The phrase "leadership and training” was incorrectly quoted by the Commission as “rank and training.” Decision Paper \#2, p. 29.

$8 \quad$ Harrell \& Miller, p. 80. 


\section{Analysis of MLDC Report}

reduce morale, especially on ships and on overseas deployments. ${ }^{9}$ The "sexualization" of the atmosphere made it difficult for colleagues to regard one another as just co-workers, they reported, thereby undermining cohesion. They describe one respondent's complaint that "the mess . . . at night [for] this unit looks more like a singles club or promenade deck than a mess hall.” Another respondent complained:

This place is like high school all over again. Everyone is dating others. To me this is not the military. We are here to do a job not meet our spouse. Guys seem more worried about getting a girl than doing their job. ${ }^{10}$

Harrell \& Miller also reported a widespread belief that double standards existed for the two sexes. ${ }^{11}$ They stated, "We heard repeatedly how double standards (e.g., different performance expectations, different responsibilities) undermine women's credibility and generate hostility from junior enlisted men, who believed that they are afforded the fewest privileges of anyone."12 Belief in double standards was enhanced by such practices as allowing women to take showers every 72 hours while in the field. One need not invoke sexism to understand the resentment "among the men, who endure a heavier workload when the women, the vehicles, and the drivers return to base so that women can take showers."13

Harrell \& Miller further reported complaints that women were more inclined than men to resist leadership-to object to being told to do something their commander's way "because he said so"-a tendency that is reasonably thought by senior enlisted and officers to "undermine[] discipline and the

Harrell \& Miller, p. 81.

Harrell \& Miller, pp. 81-82.

$11 \quad$ Harrell \& Miller, pp. 77-81.

12 Harrell \& Miller, p. xx.

$13 \quad$ Harrell \& Miller, p. 81. 


\section{Kingsley R. Browne}

rank authority system.”14 Additionally, they recount reports that senior personnel were hesitant to reprimand or discipline women, meaning that "junior females were permitted to espouse these attitudes more freely than their male colleagues." Despite their observation that "gender is one of the ways in which subordinates are now reported to be challenging or even chastising their superiors," Harrell \& Miller insisted that the problem was attributable to a "generation gap" and not to sexual integration.

Despite all of these problems, how was it that Harrell and Miller were able to conclude that integration was perceived as having a relatively small effect on cohesion and readiness? The answer is that they recharacterized the problems as problems of leadership and training rather than as problems created by integration. The attribution of problems to these other influences illustrates a form of sleight-of-hand by which any problem can be redefined as something other than what it really is. Faith in better "leadership" as the solution seems to rest on an unstated syllogism: (1) with adequate leadership, sexual integration would not be a problem; (2) sexual integration has caused problems; (3) therefore, leadership is inadequate. If leadership is inadequate, the train of logic seems to proceed, then it is not sexual integration that is the problem. With this reasoning, virtually any problem (whether sexual harassment, fraternization, lack of unit cohesion, concern about favoritism and double standards, drugs, AIDS, poor equipment, or virtually anything else) can be redefined as simply a "leadership" problem.

Harrell and Miller's study could best be characterized as concluding that sexual integration led to a number of negative effects but that these effects could be mitigated with better leadership and training. That is very different from saying that integration did not produce negative effects. Moreover, their contention that leadership and training, rather than integration itself, were the problem was largely unsupported, and the nature of the "leadership" and "training" modifications that would mitigate the problems was unspecified. What kind of leadership would it take, for example, to cause young men and

14 Harrell \& Miller, pp. 85-86. It should be noted that this finding is consistent with social-science evidence suggesting that women's norms of equality cause them to fit less comfortably into hierarchical organizations. See Benenson, J. F., \& Schinazi, J. (2004). Sex Differences in Reactions to Outperforming Same-Sex Friends. British Journal of Developmental Psychology, 22:317-333; Browne, K. R. (2007). Co-ed Combat: The New Evidence that Women Shouldn't Fight the Nation's Wars. New York: Sentinel, pp. 164-167. 
young women at the height of their reproductive lives not to perceive each other sexually and not to have those perceptions affect their behavior? Unsurprisingly, we are not told.

A similar kind of sleight-of-hand characterizes Harrell and Miller's treatment of their finding that women tended to be more resistant to authority and unwilling to take orders than men. The authors' apparent unwillingness to conclude that the problem was sex seems to have caused them, again, to recharacterize the problem as something else. So, instead of this being a "gender issue," they asserted, this sex difference really reflects a "generation gap" not a "gender gap." 15 According to the researchers, the cause of the increasingly common resistance to leadership is that the military was drawing from an undisciplined "generation that was never spanked." The trend only appeared to be related to sex, they argued, "because women are overrepresented in the younger generation." Thus, "generational differences were occasionally reported as a gender problem." Contrary to Harrell and Miller, however, women were not "overrepresented in the younger generation" of soldiers, although they were represented at a higher level than they had been in the past. They still made up only about 15 percent of the junior ranks. Therefore, if resistance to leadership were sex neutral, only about one out of seven of the "resisters" would be female and six out of seven would be men, hardly the basis for a general impression that the problem was especially associated with women.

It should also be noted that the version of the Harrell \& Miller study that was publicly released was substantially less negative about the consequences of integration than the original draft had been. Numerous changes were made between the draft version of the report and the version ultimately released by the Pentagon. ${ }^{16}$ Missing from the released version, but present in the original draft, were the following observations:

- "Pregnant single women were perceived to be a long-term burden.”

$15 \quad$ Harrell \& Miller, p. 86.

16 Scarborough, R. (1997). Pentagon Study Excises References to Pregnancy, Readiness. Washington Times, Nov. 7, p. A-3. 


\section{Kingsley R. Browne}

- "When women, especially single women, intentionally become pregnant to escape either unpleasant duties, a certain command, or a deployment, both men and women resent the additional burden they must shoulder as a consequence of their absence.”

- "Some unit commanders appear to feel pressured to report success in the training, retaining, and promotion of women. Men who perceive this believe women are given more opportunities than men to work up to the standard."

- "Women agreed that false harassment complaints are a problem, and added that they undermine the ability of women who are truly harassed to have their complaint taken seriously ....”

Even the title of the report was changed to add an upbeat perspective. The original title was the neutral, though descriptive, Recent Gender Integration in the Military: Effects Upon Readiness, Cohesion and Morale. The title of the report as released added a little spin: New Opportunities for Military Women: Effects Upon Readiness, Cohesion and Morale.

Despite Harrell and Miller's chronicling of fairly widely held perceptions that integration was causing problems, there is reason to believe that what they were told tended to understate the actual negative views. As Harrell and Miller noted, unit commanders decided who should be included in the focus groups they met with and who should not. Although Harrell and Miller explicitly acknowledged that they might have been denied access to "individuals with objectionable views," they said they had no reason to believe that this was the case. ${ }^{17}$ If it were done right, of course, they would have no way of knowing what motivated unit commanders to select particular participants.

The notion that commanders would select individuals with favorable views is not fanciful. Miller herself reported in a different study that both men and women have complained to her that when commanders select personnel to meet with representatives of DACOWITS, they "typically sent soldiers whom they knew to possess a view compatible with that of the

$17 \quad$ Harrell \& Miller, p. 106. 
DACOWITS." ${ }^{18}$ That is a perfectly understandable approach for commanders. After all, if you are a commander and you know that your fitness report will include evaluation of your attitudes toward, and success at furthering the careers of, women, you would be unlikely to send soldiers with views perceived as "Neanderthal" to meet with DACOWITS. There is no reason to think that commanders would have taken a different approach in selecting personnel to be interviewed by Harrell and Miller. Thus, the views expressed by personnel interviewed in these studies cannot be assumed to be in any way representative of the military as a whole.

In sum, the Harrell and Miller study presented abundant evidence inconsistent with its conclusion that sexual integration poses little threat to cohesion or military effectiveness. Unfortunately, the MLDC did not appear to look beyond the "spin" applied to those findings and thoughtfully examine the underlying data before making its blithe recommendation favoring complete integration.

\section{B. 2009 DACOWITS Report}

The MLDC also relied heavily on a 2009 report by the Defense Department Advisory Committee on Women in the Services, ${ }^{19}$ but that report can hardly be considered authoritative, either. The charter of DACOWITS is to provide the Secretary of Defense "independent advice and recommendations on matters and policies relating to the recruitment and retention, treatment, employment, integration, and well-being of highly qualified professional women in the Armed Forces." ${ }^{20}$ Its members may or may not have a military background. Only two of its members at the time of the 2009 report had military experience (other than as a military wife), and only one of those two had experience in the combat arms. DACOWITS has a long history of seeking to expand women's opportunities to serve in

18 Miller, L. L. (1998). Feminism and the Exclusion of Army Women from Combat. Gender Issues, 16(3):33-64, p. 40.

19 Defense Department Advisory Committee on Women in the Services (DACOWITS), 2009 Report.

20

DACOWITS Report, p. i. 
combat-related fields, so the fact that it would reach conclusions favorable to integration can hardly be a surprise. Thus, the expertise of the Committee and its conclusions are less meaningful than the quality of the data upon which it relied, and as will be seen below, the quality of the data was not good.

The DACOWITS report's primary data came from site visits conducted at eight military installations, plus two "virtual site visits" to Iraq and Afghanistan via video teleconference. Two members of the committee conducted each focus group. A total of 42 focus groups were conducted, involving 454 participants, all of whom had been deployed to Iraq or Afghanistan at least once. The report contained the following findings:

- Most focus group participants, male and female, had been involved in combat in Iraq or Afghanistan. ${ }^{21}$

- Most participants said that women serving in combat had a positive impact on the mission, because women helped accommodate cultural considerations (primarily in their interaction with female civilians), helped maintain personnel strength, and provided a "unique perspective" on the mission. ${ }^{22}$

- A majority of participants said that having women in combat "not only does not erode morale but can be a positive influence, since women often serve as confidants for male peers and are more likely than men to organize morale-boosting celebrations." ${ }^{23}$

- The overwhelming majority of participants indicated that women should be able to fill all roles in the military for which they are qualified. ${ }^{24}$

DACOWITS Report, p. 45.

22 DACOWITS Report, p. 63.

${ }^{23}$ DACOWITS Report, pp. iii, 67.

$24 \quad$ DACOWITS Report, p. 138. 


\section{Analysis of MLDC Report}

- When asked what would be legitimate reasons for not allowing women to serve in combat roles, most focus group participants cited none. $^{25}$

- The overwhelming majority of women reported that their combat experiences had influenced their future plans, mostly by causing them to want to separate from the military sooner than they had planned. ${ }^{26}$

There is no reason to think that the opinions of these focus-group participants were in any way representative of military personnel generally, or of combat-arm personnel in particular. First, the focus groups were not broadly representative of combat (or even non-combat) personnel. Women were substantially over-sampled in the focus group, with 70 percent of the participants being women, ${ }^{27}$ despite the fact that women make up only about 14 percent of Active Duty forces. Moreover, the tendency for commanders to select "DACOWITS-friendly" participants-and their incentive to do so-has already been noted. Also, because there was only one male member of the Committee at the time the data were gathered, every focus group was led by at least one woman, and in most cases two women, which would predictably have interfered with the willingness of participants, especially men, to express negative views about sexual integration and the performance of women. Laura Miller found in a study of attitudes of Army personnel that many men would initially recite the "party line" about the success of integration, and only when pressed would "their true feelings burst forth." 28 Other men would say nothing in mixed-sex groups, but when asked to stay after the group was dismissed, they would indicate that they did not feel free to state their true opinions publicly, especially in the presence of female officers.

$27 \quad$ DACOWITS Report, p. 38.

28 Miller, L. L. (1997). Not Just Weapons of the Weak: Gender Harassment as a Form of Protest for Army Men. Social Psychology Quarterly, 60:32-51, p. 48. 


\section{Kingsley R. Browne}

The actual knowledge of the focus-group participants about combat is also likely overstated. Although it sounds impressive that most female (and male) participants had served in "combat roles" in Iraq or Afghanistan-implying a general familiarity with the demands of combat-it should be noted that the definition of "combat" used by DACOWITS was exceedingly broad:

When one is physically in a combat theatre of operations where one is exposed, on a regular or irregular basis, to the possibility of hostile action from a threat, either to self or unit, requiring defensive or offensive measures which may involve the use of arms to keep from harm. ${ }^{29}$

Thus, to be deemed having served in a combat role, the minimum requirement is that the individual was in a combat theatre and someone in his unit was exposed on an irregular basis to the possibility of hostile action that required defensive measures (such as, presumably, hiding under a desk). Under this definition of combat, virtually every occupant of London served in a combat role during the Blitz. In fact, only 8 percent of female participants and 14 percent of male participants in the DACOWITS focus groups reported having fired their weapons in theater. This is not to suggest that focus-group participants did not serve ably or that their service did not involve significant risk, but it is misleading to characterize all of them as having served in "combat roles," a characterization that may result in an overestimation of their expertise about the demands of offensive ground combat.

The Committee's reporting of its results is also quite tendentious. It reports, for example, that "When asked what would be legitimate reasons for not allowing women to serve in combat roles, most focus group participants cited none.”30 That statement might cause the casual reader to conclude that most focus-group participants were unable to articulate any legitimate reason for excluding women from ground combat. Yet that is not what the Committee's statement necessarily means. It may just mean that when the

\footnotetext{
29 DACOWITS Report, p. 45

30 DACOWITS Report, p. iii.
} 
question was raised only a few participants affirmatively volunteered answers, which is not at all inconsistent with many participants' holding negative views about sexual integration. For example, the fact that most participants did not respond to the question would signal their beliefs only if we could take their silence as indicating a belief that no such reasons existed. But we do not know how respondents answered other open-ended questions, so we cannot know whether the failure to volunteer a response was indicative of a belief that no valid reasons existed or consistent with the way other questions were responded to. Moreover, even if a majority of individuals in a focus group believed, for example, that sexual issues or women's relative lack of strength were valid reasons to exclude women, once those issues had been identified by just one participant, the reasons would be on the table, and participants may not have thought that any purpose was served by listing an objection that had already been mentioned. There is no indication in the DACOWITS report that after particular reasons were mentioned there was any polling to determine how widely shared those views were in the group. Moreover, Laura Miller's finding that participants (especially men) in such groups are reluctant to make statements that could be viewed as "antiwoman" has already been noted. Despite the inconclusive nature of what was being reported, the Committee saw fit to employ the "most focus group participants cited none" locution three times, once in the Executive Summary and twice in the body of the report. ${ }^{31}$

Despite DACOWITS's repeated statements that most participants did not volunteer reasons for excluding women from combat, and despite the fact that it stated that it found "little evidence that the organizational performance of the military has been negatively impacted," 32 the report actually contains a variety of statements suggesting that some participants did in fact entertain substantial reservations. For example, the report stated:

A minority of participants, most of whom were male, expressed that having females in combat negatively impacts unit morale. They cited reasons such as sexual tension and harassment, female emotionality,

\footnotetext{
$31 \quad$ DACOWITS Report, pp. iii, 77, 79.

32 DACOWITS Report, p. 11.
} 


\section{Kingsley R. Browne}

having to exercise discretion or decorum to avoid offending females, and differential Physical Training (PT) standards. ${ }^{33}$

The report then quoted a number of focus-group participants expressing concerns about men's being distracted by the presence of women ${ }^{34}$ men's desire to protect women, women's lesser physical strength and consequent inability to do the job as well as men, the impact on personnel strength that results when women get pregnant (sometimes deliberately) and either not deploying or being sent home as a consequence, as well as logistical issues such as hygiene. ${ }^{35}$ If one read only the Executive Summary of the DACOWITS report, one would remain blissfully ignorant of these concerns.

DACOWITS also relied heavily on anecdotal accounts in newspaper stories lauding the success of integration in Iraq and Afghanistan. The report uncritically cites as authority a New York Times article stating that women "have reshaped life on bases across Iraq and Afghanistan ... And they have done so without the disruption of discipline and unit cohesion that some feared would unfold.. . . ."36 This conclusion seems to be based solely on interviews with people that the reporter chose to talk to from among those he was allowed to talk to. The Committee quoted that same article for the proposition that women are "as much at risk as any male counterpart," and also quoted another Times article that reported that in both Afghanistan and Iraq "women have done nearly as much in battle as their male counterparts." ${ }^{37}$ Without minimizing the contribution of women who served in Iraq and Afghanistan, it is preposterous to argue that men and women were equally involved in battle and faced equal risks, given the fact that despite women's making up about $11 \%$ of the personnel who served there, they account for only about $2 \%$ of those killed in action and less than $2 \%$ of those

33 DACOWITS Report, p. 68.

34 DACOWITS Report, p. 65.

35 DACOWITS Report, p. 65-74.

36 Myers, S. L. (2009). Women at Arms: Living and Fighting Alongside Men, and Fitting In. New York Times, August 16.

37 Alvarez, L. (2009). Women at Arms: G.I. Jane Breaks the Combat Barrier. New York Times, August 16. 
evacuated for battle-related reasons. A male soldier was 5.5 times as likely to be killed as a female one, suggesting that the magnitude of risk to which the two sexes were exposed was, in fact, quite different.

The articles in the Times, and many others like them, have one thing in common: They do not contain a single quotation from anyone opposing the further integration of women in combat. Given that polls, private conversations, message-board postings, and even the RAND and DACOWITS reports themselves routinely demonstrate widespread opposition to sexual integration of combat units by men in ground-combat specialties, one can only conclude that these stories do not tell the whole story, whether because of bias in the selection of interview subjects, reluctance of active-duty military personnel to speak candidly, or bias on the part of the reporters or their publications. Whatever the reason, these stories cannot be viewed as neutral accounts of women's experience or of the opinions of military personnel. Of course, when the press narrative strays from touting the success of sexual integration to decrying the terrible treatment that military women receive, then we hear stories of rape, sexual harassment, PTSD, and lack of acceptance of women (all things that would be expected to dramatically disrupt cohesion and degrade unit performance but are never identified as doing so), but these two kinds of stories remain strongly compartmentalized. ${ }^{38}$

The DACOWITS report itself resembles the above-mentioned news accounts. For example, it notes that "concerns have been raised in the press and by retired military commanders about the potential impact of women in combat on mission performance, unit cohesion, and the well-being of the

38 See Broadbent, L. (2011). Weekend: A Female Soldier in Iraq Is More Likely to Be Attacked by a Fellow Soldier than Killed by Enemy Fire: Rape in the US Military-America's Dirty Little Secret. Guardian (London), Dec. 10, p. 55; Dribben, M. (2011). Military Struggles with Abuse of Female Troops. Pittsburgh Post-Gazette, Sept. 18, p. B-6; O’Connor, P. (2011). Ft. Wood Sexual Assaults Persist: Six Years after Pentagon Committed to Addressing Such Crimes Within the Ranks, They Remain a Fixture. St. Louis Post-Dispatch, Jan. 30, p. A-1; Ode, K. (2010). Sexual Trauma: Women Vets' Secret War: 66,342 Female Veterans Report Assaults from 2002 to 2008-By Their Band of Brothers. Star Tribune (Minneapolis), Dec. 18, p. 1A; Terry, D. (2009). Abuse of Women Is Ugly Side of U.S. Military. Chicago Sun-Times, June 4, p. 19. 
women involved (e.g., in areas such as hygiene and health care), ${ }^{39}$ but it does not actually cite any specific individuals who have raised those concerns or the specific basis for those concerns, leaving the impression that these are just vague and probably baseless allegations. When it refers to arguments about the impact of women on mission accomplishment, effects on cohesion, and sexual behavior between service members, it cites only to publications that critique those arguments, rather than to the arguments made by those raising concerns. ${ }^{40}$ As far as one can tell, it never bothered actually considering the arguments themselves. That is no way to become educated on a subject. Surely, one could not reasonably evaluate the theory of anthropogenic global warming solely by relying on the characterization of the theory by its opponents or evaluate the anti-warming arguments by relying solely on the characterization of the theory's proponents. In short, the DACOWITS report simply cannot be taken seriously as a rigorous examination of the issues that it purported to deal with.

The DACOWITS report dismissed concerns raised by a minority of participants ("little evidence" ${ }^{\text {"11 }}$ ) as if they were insignificant if not endorsed by a majority. However, group dynamics such as morale and cohesion are not determined by a democratic vote. If, for example, two-thirds of group members think that morale and cohesion are high, and one-third think that morale and cohesion are low, it is the one-third who are correct. Moreover, it is far from clear what standard of proof the Committee is applying. For example, it says that "there has been no demonstrated impact on military performance" ${ }^{\$ 2}$ as a consequence of pregnancies. Yet, the report itself cites concerns raised about pregnancy and its effect on the mission. As discussed below, the Army has been extremely reticent about losses due to pregnancy; indeed, it has maintained that it is not even tracking the information. So, it is hardly surprising that there has been no demonstrated impact, as it is not clear that anyone has even sought to measure it. But surely the answer then is not to conclude that there is no impact simply because no one has bothered

39

41

42

DACOWITS Report p. 11.

DACOWITS Report p. 12.

DACOWITS Report p. 11.

DACOWITS Report p. 13. 
to look. Instead, the more responsible course would be to attempt to analyze existing data, and, if inadequate data exist, to gather better data.

In sum, the DACOWITS report is not a serious examination of the issue of women in combat and is not worthy of serious consideration in setting manpower policy.

\section{Anecdotal Reports}

The MLDC also appears to have relied heavily on select anecdotal reports from the field. For example, it states that "Servicemembers and commanders returning from Iraq, when questioned about the assignment policy, consistently informed researchers that both male and female servicemembers had performed well." ${ }^{43}$ This blanket statement is meaningless. It cannot mean that all service members performed well, since there are always poor performers in large organizations. For example, the statement cannot be taken to mean that those involved in the misconduct at Abu Ghraib performed well. If the statement means that some male and some female service members performed well, that also does not tell us anything meaningful, as one would assume that most service members performed well-that is, at some acceptable level. Even we were to give the Commission the benefit of the doubt and assume that what the statement means is that men as a group and women as a group performed equally well, that would not mean that sexual integration did not have negative effects, as much of the concern about integration involves reduction in unit effectiveness-that is, concern that the presence of women diminishes the effectiveness of the entire unit, including men in the unit. In any event, these bland statements are so detached from any empirical foundation as to be worthless.

In fact, the DACOWITS report, upon which the MLDC appeared to place substantial weight, makes it quite clear that the views of service members who had served in Iraq were not consistently favorable, although DACOWITS did its best to downplay those results. As noted above, a

43 Military Leadership Diversity Commission (2010). Women in Combat: Legislation and Policy, Perceptions, and the Current Operational Environment, Issue Paper \#56 , p. 3. 
number of male focus group participants did in fact register specific complaints about female performance:

[T] hey said the mission impact was negative, for reasons including men being distracted by women and wanting to protect them, women not being as physically strong and therefore not able to do the same job as a man, logistical issues such as hygiene, and women impacting personnel strength by getting pregnant and then sent home. ${ }^{44}$

It is unclear how to square the description of the views of these male participants with the Commission's implication that reports from those who served in Iraq and Afghanistan were consistently favorable.

\section{THE COMMISSION'S TREATMENT OF MANY ISSUES IS SERIOUSLY DEFICIENT}

Those raising concern about sexual integration have identified a large number of problems that the MLDC gave scant, if any, attention. Three of these are:

- Women's relatively lesser strength

- Pregnancy and motherhood, especially single motherhood

- The effect of the introduction of women on cohesion of formerly allmale groups

\section{A. Strength and Physical Capacity}

The Commission's treatment of the issue of physical strength differences was cursory at best. The word "strength"-in the context of physical strength and not in the sense of "the strength that comes with diversity"-does not appear in the Commission's report. The subject of physical differences

DACOWITS Report, p. 73. 
between the sexes is addressed in MLDC Issue Paper \#56, however, but is given short shrift. The entirety of the discussion is as follows:

Another argument is that women in combat impede mission effectiveness because they cannot handle the same equipment or tolerate the same physical stress as men. Indeed, women get the same training and must meet generally the same health standards and qualifications as men, although sometimes the physical requirements differ. For example, the Army Physical Fitness Test, which consists of push-ups, sit-ups, and a two-mile run, uses the same scale to score sit-ups for both genders, with an easier scale for females in push-ups and the run (APFT-standards.com, 2010). According to one female soldier, however, varying fitness expectations "automatically sets women soldiers apart and makes us appear less capable than men" (Ross, 2010). When it comes to arguments about carrying equipment or even wounded soldiers, some argue that inability may be more a function of size than gender, and that the capabilities of smaller men and larger women overlap. Ultimately, there is a lack of empirical data on female fitness and correlation with battle performance other than basic physical requirements by the Services. ${ }^{45}$

The Commission's Decision Paper \#2 cites Issue Paper \#56 for the proposition that "there is not much direct evidence to support claims that all women lack the physical ability to perform in combat roles. In fact, women and men have overlapping physical capabilities." ${ }^{\prime 4}$

The Commission's treatment of the physical capacity issue is incomplete and misleading in a number of respects. First, although it acknowledges that "sometimes the physical requirements differ" between the sexes, it gives no clue about just how great these differences are. In fact, they are huge. The table below shows the difference between the requirements for men and those for women in order to score 100 points on the Physical Fitness Test:

\footnotetext{
45 Issue Paper \#56, p. 3 (emphasis added).

46 Decision Paper \#2, p. 30.
} 
Standards for U.S. Army Physical Fitness Test ${ }^{47}$

\begin{tabular}{|c|c|c|c|c|c|c|c|c|c|c|}
\hline \multirow{3}{*}{ Activity } & \multicolumn{10}{|c|}{$\overline{\text { Age }}$} \\
\hline & \multicolumn{2}{|c|}{$17-21$} & \multicolumn{2}{|c|}{$27-31$} & \multicolumn{2}{|c|}{$37-41$} & \multicolumn{2}{|c|}{$47-51$} & \multicolumn{2}{|c|}{$52-56$} \\
\hline & $\mathrm{M}$ & $\mathrm{F}$ & $\mathrm{M}$ & $\mathrm{F}$ & $\mathrm{M}$ & $\mathrm{F}$ & $\mathrm{M}$ & $\mathrm{F}$ & $\mathrm{M}$ & $\mathrm{F}$ \\
\hline Sit-ups & 78 & 78 & 82 & 82 & 76 & 76 & 66 & 66 & 66 & 66 \\
\hline Push-ups & 71 & 42 & 77 & 50 & 73 & 40 & 59 & 34 & 56 & 31 \\
\hline $\begin{array}{l}\text { 2-Mile Run } \\
\text { (min:sec) }\end{array}$ & $13: 00$ & 15:36 & 13:18 & $15: 48$ & 13:36 & $17: 00$ & $14: 24$ & $17: 36$ & $14: 42$ & 19:00 \\
\hline
\end{tabular}

As can be seen from the table, men and women are, as the Commission notes, required to do the same number of sit-ups. ${ }^{48}$ However, the requirements for the other tasks are substantially different by sex. The average male requirement for push-ups across age groups is 72 percent higher than it is for females. As for running, a 20-year-old woman is given almost a full minute more to run two miles than a 56-year-old man is, and a 56-year-old woman is given over four minutes longer than a man of the same age. These differences in standards are unsurprising, given the fact that empirical data clearly reveal (also unsurprisingly) that men are substantially stronger than women. In fact, there is less overlap in strength between the sexes than there is in height. Indeed, the probability that a man selected at random from the population will have greater upper-body strength than a randomly selected woman is somewhere between 95 and $99 \% .{ }^{49}$ (If there were no overlap at all between the groups, of course, then the probability would be $100 \%$ ).

472011 Army (APFT) Standards, http://apft-standards.com/pushup-male.html; http://apft-standards.com/pushup-female.html; http://apft-standards.com/situp-male.html; http://apft-standards.com/situp-female.html; http://apft-standards.com/run-male.html; http://apft-standards.com/run-female.html.

48 It is worth noting, however, that equal numbers of sit-ups for men and women do not equate to equal strength. The male center-of-gravity is substantially higher than that of women, so a sit-up requires men to lift a greater proportion of their body weight than is the case with women.

49 Browne, Co-ed Combat, pp. 23-24. 
The Commission further suggests that "inability may be more a function of size than gender," and that the capabilities of smaller men and larger women overlap." ${ }^{50}$ Significantly, the authority for that proposition is merely to note that "some argue," without providing any source for the assertion in order to determine whether there is actually any empirical basis for the argument. At a trivial level, the statement is true: the smallest, weakest men are weaker than the largest strongest women, although the smallest, weakest men are unlikely to volunteer for the military. The extent of overlap, however, is fairly small, with perhaps the strongest ten percent of women being stronger than the weakest ten percent of men. ${ }^{51}$ So, one question is simply whether there is enough overlap in strength to make a policy change worthwhile.

To the extent that the Commission's implication is that the difference between the sexes in strength is solely a consequence of men's greater size, it is manifestly false. It is true that, all else being equal, men and women with equal lean body mass (or "fat-free weight") have largely equivalent strength, as male and female muscular tissue is virtually identical. But men and women of equal size have very different lean body mass. That is, a part of the reason that men, on average, are stronger than women, on average, is that they are bigger. But another significant reason is that a substantially greater proportion of male weight comes from muscle, with a correspondingly lesser proportion being made up of fat.

The fundamental difference between men and women in musculature and fat distribution is largely due to male and female sex hormones. ${ }^{52}$ Testosterone increases muscle mass, which in turn increases strength. Testosterone levels are also associated with a reduction in body fat, especially subcutaneous fat. As many male beer drinkers have come to learn,

$50 \quad$ Issue Paper \#56, p. 3.

51 Goldstein, J. S. (2001). War and Gender: How Gender Shapes the War System and Vice Versa. Cambridge: Cambridge University Press, p. 160.

52 Herbst K.L. \& Bhasin, S. (2004). Testosterone Action on Skeletal Muscle. Current Opinion in Clinical Nutrition and Metabolic Care, 7:271-277; Cheuvront, S. N., Moffatt, R. J., \& DeRuisseau, K. C. (2002). Body Composition and Gender Differences in Performance. In Wolinksy, I., \& Driskell, J. A. (eds.), Nutritional Assessment of Athletes, pp. 177-200, Boca Raton, FL: CRC Press. 


\section{Kingsley R. Browne}

however, it does not decrease abdominal fat. Rather, it is estrogen that inhibits deposition of fat in the abdomen, although it increases it in the breasts, thighs, and buttocks. ${ }^{53}$ Thus, the sex difference in strength is much more than just a sex difference in overall size. That is to say, as between men and women of equal weight, men will be substantially stronger, especially with respect to the upper body, where a disproportionately large amount of male muscle is found.

As previously noted, the Commission's Issue Paper \#56 reported that "there is not much direct evidence to support claims that all women lack the physical ability to perform in combat roles." As is so frequent in the Commission's work, it is setting up a straw man. It does not cite any source for these claims, and it is extremely unlikely that any responsible person has ever made the absolute claim the Commission labors to reject. Contrary to the implication of the Commission, however, there is much evidence to support claims that almost all women lack the physical ability to perform ground-combat roles, although there is no indication in any of the Commission's documents that it made any effort to find such evidence. The Commission could have consulted, for example, an extensive study conducted by the British Ministry of Defence in 2002. That study made findings that were quite relevant to the Commission's analysis. It concluded:

The overwhelming majority of females applying to the Army or currently serving in the Army would be physically incapable of performing many of the tasks required by the Infantry and RAC [Royal Armoured Corps]. Among the remainder who might achieve the required standards, the risk of injury will be higher than among their male counterparts, as these individuals will be working at a higher percentage of their maximum capability, and their reserve capacity will be less.

However, there remains a tiny minority of women estimated at 0.1 percent of recruits and 1 percent of trained soldiers who could

\footnotetext{
53 Björntorp P. (1991). Adipose Tissue Distribution and Function. International
} Journal of Obesity, 15(Suppl. 2):67-81. 


\section{Analysis of MLDC Report}

probably achieve the required standards and perform the job effectively without sustaining higher rates of injury. ${ }^{54}$

A U.S. Navy study in the 1980s reached similar conclusions. Examining sex differences in ability to perform damage-control tasks at sea-some of the most physically demanding, yet critical tasks, that shipboard personnel are called upon to perform-the study found that "while clear majorities of women (more than 90 percent in some cases) failed to meet the physical standards for eight critical shipboard tasks, virtually all the men passed (in most cases 100 percent). ${ }^{, 55}$ One percent of women but 96 percent of men, for example, could carry water pumps to the scene of a fire or flooded compartment.

There we have it. One out of one thousand British female recruits were estimated to have the potential to achieve the standards required for ground combat and to perform without sustaining higher rates of injury. Thus, when the Commission complains about the combat exclusion's elimination of half the recruiting pool for the military ${ }^{56}$ its claims bears little relationship to reality. Of course, there is no indication that the Commission even considered any of this data, anyway.

Strangely, in the Branching and Assignments Decision Paper, the Commission acknowledges that "any likely gender-neutral physical standard for combat or entry into tactical fields, as is recommended by the Commission, would disqualify a higher percentage of women than men," 57 but does not go on to examine the obvious question that follows from this observation: how big would the disparity be? The answer to that question is highly relevant to what the policy should be. If almost no women can satisfy gender-neutral standards, as was the UK experience, then all of the changes made to accommodate women throughout the ground-combat arms will

54 Ministry of Defence (United Kingdom). (2002). Women in the Armed Forces. Report by the Employment of Women in the Armed Forces Steering Group, p. B-5.

55 Presidential Commission, 1992, p. 74.

$56 \quad$ MLDC Report, p. 56.

57 Decision Paper \#2, p. 30, note 33. 


\section{Kingsley R. Browne}

produce very little “diversity” benefit, no doubt leading to pressure to reduce standards in order to allow sufficient women to pass.

\section{B. Pregnancy}

Many who have raised questions about women's participation in combat have argued that pregnancy presents a substantial readiness challenge. ${ }^{58}$ Concerns have already been mentioned about the effects of pregnancy on readiness and about the fact that women sometimes intentionally become pregnant to avoid deployment, issues that were raised in the 1997 RAND report (although largely excised from the released version) and by focusgroup participants in the DACOWITS study. Yet, the words "pregnant” and "pregnancy" do not appear in the Commission's report, nor can they be found in the documentation supporting its recommendation to drop the combat exclusion. ${ }^{59}$ The Decision Paper dealing with retention does acknowledge that one of the reasons for women's greater first-term attrition is pregnancy, but the Commission does not connect that fact to military readiness. ${ }^{60}$ Nonetheless, the Commission casually recommends eliminating the combat restriction, apparently oblivious to the detrimental effects of pregnancy on the readiness of combat units.

Reliable statistics on military pregnancies are not easy to get, but a reasonable estimate is that around ten percent of military women are pregnant

\footnotetext{
58 Browne, Co-ed Combat; Gutmann, S. (2000). The Kinder, Gentler Military: Can America's Gender-Neutral Fighting Force Still Win Wars? New York: Scribner.

$59 \quad$ Issue Paper \#56; Decision Paper \#2.

60 The word "pregnancy" also appears in two other Commission documents, both times in footnotes observing that courts have held that sometimes pregnancy is a legitimate basis for differential treatment between the sexes. Military Leadership Diversity Commission, Introduction to Laws Governing Diversity Policies, Issue Paper \#35, p. 4, note 4; Narrow Tailoring and Diversity Policy, Issue Paper \#37, p.4, note 1. In neither case was any connection noted between pregnancy and readiness.
} 


\section{Analysis of MLDC Report}

at any one time, ${ }^{61}$ differing somewhat by branch and rank. A comprehensive Navy study of over 6,000 female crew members aboard 53 ships found an overall pregnancy rate of 19 percent per year. ${ }^{62}$ The highest pregnancy rate (27 percent) was on submarine tenders, the class of ships with the largest number of women. A study of women in the Air Force-the service with the highest proportion of women-found that about twelve percent of women had one or more pregnancies in the study year. ${ }^{63}$

There is good reason to believe that pregnancy does have a negative effect on readiness, and that effect is likely substantial. As a nation, we are fortunate that when duty calls for the troops, it usually calls overseas. But when overseas deployment is required, the non-deployability rate for women is three to four times the rate for men, the difference being largely due to pregnancy. ${ }^{64}$ Once a soldier is confirmed to be pregnant she becomes 'nondeployable' and will remain so for up to a year. In the Navy, a new mother is not assigned to sea duty for a full twelve months. After deployment, many women must be sent back home because of pregnancy. According to the Pentagon, over five percent of all military women deployed during the Gulf War became pregnant, even though most were in the Gulf for far less than a year. ${ }^{65}$ A 1999 study by the Center for Naval Analyses reported that "a quarter of women and a tenth of men are lost from ships every year for unplanned reasons.” Losses from pregnancy alone were eleven percent,

61 Military Operational Medicine Research Program. (1999). Health and Performance Research for Military Women: The 1994 Defense Women's Health Research Program (DWHRP94). MOMRP Fact Sheet Number 9, USAMRMC.

62 Garland, F. C., Garland, C. F., \& Gorham, E. D. (2000). A Model of Expected Occurrence of Adverse Pregnancy Outcomes Aboard U.S. Navy Ships. Military Medicine, 165:691-697.

63 Robbins, A. S., Chao, S. Y., Frost, L. Z., \& Fonseca, V. P. (2005). Unplanned Pregnancy among Active Duty Servicewomen, U.S. Air Force, 2001. Military Medicine, 170:38-43.

64 Presidential Commission, p. 20; Bucher, M. A. (1999). The Impact of Pregnancy on U.S. Army Readiness. AU/ACSC/016/1999-04. Air Command and Staff College, Air University.

65 Gertz, B. (1996). Dozens of GIs in Bosnia Pregnant: Army Bans Booze, Doesn’t Curb Sex. Washington Times, July 18, p. A-1. 


\section{Kingsley R. Browne}

meaning that there were more female losses due to pregnancy than there were male losses altogether and also that there were more female losses due to causes other than pregnancy than there were total male losses. ${ }^{66}$

Despite the obvious relationship between pregnancy and readiness, the military does not seem to have, or at least is not willing to release, information concerning the question. When asked how many women had been shipped home from Iraq because of pregnancy, a spokesman for Central Command asserted, "We're definitely not tracking it."67 An Army spokeswoman at the Pentagon said that the Army does not "release" information on those who leave the war theater, implying that the information is tracked, simply not released to the public. The Army's reticence on this issue goes back a long time. In 1997, Sara Lister, thenAssistant Secretary of the Army for Manpower and Reserve Affairs, candidly stated that the Army does not publicly discuss strength and pregnancy issues because "those subjects quickly became fodder for conservatives seeking to limit women's role in the Army." ${ }^{, 68}$ In other words, evidence that women may not be as capable as men in combat roles or that their inclusion will result in a decline in readiness must be suppressed because it might be influential in setting policy. Before advocating the kind of major shift suggested by the MLDC, one might have thought that it would exhibit some curiosity about this subject.

Unlike the MLDC report, the 2009 DACOWITS report did cite some data about pregnancy in support of its contention that pregnancy has had "no demonstrated impact on military performance." ${ }^{\prime 69}$ However, the DACOWITS treatment was extremely superficial, and it is doubtful that its data are accurate or complete. The report states:

66 Garcia, F. E. (1999). Women at Sea: Unplanned Losses and Accession Planning. CRM 98-182. Alexandria, VA: Center for Naval Analyses.

67 Scarborough, R. (2004). Pregnant Troops Leave the War: Central Command not Counting. Washington Times, June 16, 2004, p. A1.

68 Richard J. Newman, Army Sex Ed 101: Lessons from Racial Integration Could Ease Gender Wars. U.S. News \& World Report, Aug. 11, 1997.

69

DACOWITS Report, p. 13. 
Data prepared by the Armed Forces Health Surveillance Center show that in 2008, less than one percent (0.93\%) of deployed women had a pregnancy-related theatre medical encounter, and only 5 (less than a tenth of one percent) had pregnancy-related medical evacuations. (Data sources: Theater Medical Encounters (TMDS), TRAC2ES, and DMSS) ${ }^{70}$

There is reason to think that the number reported for "pregnancy-related theatre medical encounters" cannot be the full number of women who became pregnant. First, the reported percentage is at least an order of magnitude smaller than the number of pregnancies reported in most other surveys. Second, DACOWITS reports that the number of women who had pregnancy-related medical evacuations was approximately one-tenth of the number of pregnancies reported. If the number of medical encounters is the total number of pregnant women, that would mean that approximately one in ten pregnant women were medically evacuated for pregnancy. However, medical evacuation is costly (perhaps $\$ 10,000^{71}$ ) and reserved for serious medical conditions, so it seems unlikely that ten percent of pregnancies would have presented such substantial complications as to require medical evacuation. Finally, although DACOWITS asserts that only five women had pregnancy-related medical evacuations in 2008, the Armed Forces Health Surveillance Center reports that during the ten-year period from October 2001 through September 2010, 318 women were medically evacuated for pregnancy or childbirth, ${ }^{72}$ leading one to wonder why the ten-year average was six times as high as the one year that DACOWITS chose for its report.

Despite DACOWITS's assertion that pregnancy has had no "demonstrated impact" on military performance, researchers who have actually studied the matter have reached contrary conclusions. A report

70 DACOWITS Report, p. 13, note 36.

71 Albright, T. S., Gehrich, A. P., Wright, J. Jr, Lettieri, C. F., Dunlow, S. G., \& Buller, J. L. (2007). Pregnancy during Operation Iraqi Freedom/Operation Enduring Freedom. Military Medicine, 172:511-514.

72 Armed Forces Health Surveillance Center, Causes of Medical Evacuations from Operations Iraqi Freedom (OIF), New Dawn (OND) and Enduring Freedom (OEF), Active and Reserve Components, U.S. Armed Forces, October 2001- September 2010. Medical Surveillance Monthly Report, 18(2), Feb. 2011. 
prepared by Army Major Merideth Bucher at the Air Command and Staff College of the Air University makes a strong case that pregnancy is a serious problem. ${ }^{73}$ Major Bucher reported that women have nearly four times as much lost time as men, mostly because of pregnancy, and she cites a report from the Center for Army Lessons Learned indicating that in some units at the time of the Gulf War, 18 to 20 percent of female soldiers were nondeployable either because of pregnancy or other physical problems. She also cited the complaint of a battalion commander in the Gulf that one-third of his women could not deploy or were sent home early because of pregnancy, the most common reason for women's evacuation from the Gulf. Moreover, in their study of pregnancy in Iraq and Afghanistan, Albright and colleagues reported in 2007 that "over the past 14 years, unintended pregnancies have had a significant impact on military operations in the combat zone." 74 Wholly apart from the social dynamics created by pregnancy, simply the number of personnel who fail to deploy or who are lost to pregnancy after deployment indicates a substantial readiness problem.

\section{The Effect of Integration on Cohesion}

The MLDC gave only cursory treatment to the issue of the impact of sexual integration on cohesion, stating in its Branching and Assignments Decision Paper that "[t]o date, there has been little evidence that the integration of women into previously closed units or occupations has had a negative impact on important mission-related performance factors, such as cohesion." ${ }^{75}$ In addition to cursory discussion of the previously mentioned RAND and DACOWITS reports, the only authority cited for this proposition is a female pilot's statement that in her opinion women have not reduced cohesion. ${ }^{76}$ Again, the Decision Paper on Branching and Assignments seemed to take comfort in the fact that DACOWITS reported that "a

\footnotetext{
73 Bucher, 1999.

$74 \quad$ Albright et al., 2007.

$75 \quad$ Decision Paper \#2, p. 42.

76 McSally, M. (2007). Women in Combat: Is the Current Policy Obsolete? Duke Journal of Gender Law \& Policy, 14:1011-1059.
} 


\section{Analysis of MLDC Report}

majority" of focus-group participants reported that inclusion of women did not have an adverse effect on morale, although some believed that it did. ${ }^{77}$ Finally, the benefits to morale cited by DACOWITS participants-organizing birthday parties and providing confidantes for fellow soldiers-may or may not translate to battlefield effectiveness-or, put another way, those benefits may or may not outweigh other costs to cohesion created by integration.

One way that sexual integration can diminish cohesion is by reducing discipline. It was precisely this effect that led the Federal Advisory Committee on Gender-Integrated Training and Related Issues (Kassebaum Baker Committee) to unanimously recommend the elimination of sexually integrated basic training in 1997 (although the Secretary of Defense rejected the recommendation). That body found that integration led to "less discipline, less unit cohesion and more distraction from the training programs." ${ }^{78}$ More recent anecdotal reports support the lack of discipline within sexually integrated units. ${ }^{79}$ There is no indication that the MLDC considered any of these sources.

There are other sources of information that the Commission could have consulted, as well. For example, a 2000 study by the Center for Strategic and International Studies reported "significant perception problems" about the job performance of female personnel, and it expressed surprise that a significant percentage of women were skeptical about the performance of female service personnel. ${ }^{80}$ The study also reported that focus group discussions revealed more concern about female job performance and the impact of sexual integration on unit cohesion than many studies in the past had suggested.

\footnotetext{
77 It should also be noted that "morale” and "cohesion” are not necessarily the same thing. Manning, F. J. (1991). Morale, Cohesion, and Esprit de Corps, in Gal, R., \& Mangelsdorff, A.D. (Eds.), Handbook of Military Psychology, pp. 453-470, New York: John Wiley \& Sons

78 Priest, D. (1998). Defense Chief Opposes Separating Sexes in Basic Training. Washington Post, June 9, p. A-9.

79 Browne, Co-ed Combat.

80 Center for Strategic and International Studies. (2000). American Military Culture in the Twenty-First Century.
} 


\section{Kingsley R. Browne}

Studies conducted by psychologist Leora Rosen have similarly found that inclusion of women in army units can reduce cohesion, reporting that "overall patterns indicate a consistent negative relationship" between the percentage of women and unit cohesion. ${ }^{81}$ Of particular significance to the question of women in ground-combat units is the finding that the negative impact of women increases as the extent of physical danger increases.

Rosen and colleagues found that the dynamics of cohesion differ between the field and garrison. They found that increased time in the field was positively correlated with "group hypermasculinity"-defined as “expressions of extreme, exaggerated, or stereotypic masculine attributes and behaviors"-in both all-male groups and mixed-sex groups. ${ }^{82}$ In mixed-sex groups, field duty time was associated with decreased acceptance of women. The researchers attributed this association to the fact that the field environment "is likely to emphasize 'warrior' values of toughness, independence, and aggression.” In male-only groups, hypermasculinity was associated with both increased vertical and horizontal cohesion and readiness. They concluded that "overall military organizational effectiveness was thus still positively associated with a culture of hypermasculinity, even with the inclusion of mixed gender units and the cultural changes that they may have experienced." They concluded that "ungendered professionalism," which has positive effects in the garrison environment, "may be difficult to maintain in the field where a warrior culture is likely to develop, a culture that may be necessary for the successful accomplishment of the mission.”

Caution should be exercised in making important policy decisions based upon an assumed lack of relationship between sexual integration and cohesion. One problem with laboratory measures of cohesion is that they may not be capturing the aspect of cohesion that is militarily important. ${ }^{83}$

81 Rosen, L. N., Bliese, P. D., Wright, K. A., \& Gifford, R. K. (1999). Gender Composition and Group Cohesion in U.S. Army Units: A Comparison Across Five Studies. Armed Forces \& Society, 25:365-386.

82 Rosen, L. N., Knudson, K. H., \& Fancher, P. (2003). Cohesion and the Culture of Hypermasculinity in U.S. Army Units. Armed Forces \& Society, 29:325-351.

83 Manning, F. J., \& Fullerton, T. D. (1988). Health and Well-Being in Highly Cohesive Units of the U.S. Army. Journal of Applied Social Psychology, 18:503-519. 
Cohesion is viewed by the military as a "performance enabler" rather than a "performance enhancer." ${ }^{84}$ It correlates with military performance "by maintaining the organized group at its tasks in the face of severe stresses of battle." ${ }^{85}$ Because sociological studies of cohesion generally do not take place in particularly stressful conditions, their results may substantially underestimate the importance of cohesion in the primary circumstances in which it matters most.

\section{MISCELLANEOUS ISSUES IGNORED BY THE COMMISSION}

There are a number of other issues that were apparently completely ignored by the MLDC, and they will not be explored at length here, but they should be considered by any serious study of sexual integration. ${ }^{86}$ These include:

- The impact on mission achievement caused by male protectiveness toward women ${ }^{87}$

- The impact of female prisoners of war, especially those who are kept for a substantial period of time ${ }^{88}$

84 Griffith, J. (2007). Further Considerations Concerning the Cohesion-Performance Relation in Military Settings. Armed Forces \& Society, 34:138-147.

85 Marlowe, D. H. (1979). Cohesion, Anticipated Breakdown, and Endurance in Battle: Consideration for Severe and High Intensity Combat. Walter Reed Army Institute of Research, Neuropsychiatry Division. Washington, DC (as cited in Griffith, 2007). Combat.

86 For a more thorough discussion of all of these issues and more, see Browne, Co-ed

87 Browne, Co-ed Combat, p. 183-193.

88 Browne, Co-ed Combat, p. 235-241. 


\section{Kingsley R. Browne}

- The impact of sexual and romantic relationships within combat units, including jealousy, favoritism, and frustration, in addition to the seemingly perpetual sex scandals that the military has endured ${ }^{89}$

- The adverse effects of double standards on morale ${ }^{90}$

- The question whether women can effectively lead men in the crucible of active ground combat ${ }^{91}$

- The question whether men find it difficult to trust women in dangerous circumstances ${ }^{92}$

- Single parenthood, which is much more of a problem for female soldiers than for males ${ }^{93}$

- Hygiene issues, a concern that is sometimes ridiculed but is nonetheless serious ${ }^{94}$

89 Browne, Co-ed Combat, pp.194-207; Browne, K. R. (2007). Military Sex Scandals from Tailhook to the Present: The Cure Can Be Worse than the Disease. Duke Journal of Gender Law \& Policy, 14:749-789.

92 Browne, Co-ed Combat, pp. 169-175; Browne, K. R. (2012). Band of Brothers or Band of Siblings? An Evolutionary Perspective on Sexual Integration of Combat Forces, in Todd K. Shackelford \& Viviana Weekes-Shackelford (eds.), Oxford Handbook of Evolutionary Perspectives on Violence, Homicide, and War, Oxford University Press, pp. 372-392.

93

94 Browne, Co-ed Combat, pp. 257-260; Wardell, D. W., \& Czerwinski, B. (2001). A Military Challenge to Managing Feminine and Personal Hygiene. Journal of the American Academy of Nurse Practitioners, 13:187-193. 


\section{Analysis of MLDC Report}

- Potential recruitment and retention issues for women, as women learn that they can be involuntarily assigned to combat duties, including potential exposure of women to the draft should a draft be reinstated ${ }^{95}$

- Potential recruitment and retention issues for men, as many, if not most, men in combat arms oppose inclusion of women. Many feel betrayed by their leaders, as they believe that equal opportunity is "trumping" military effectiveness, which, for many, means that equal opportunity is viewed by the leadership as more important than their lives. $^{96}$

All of these are serious issues that should be considered before embarking on the policy change advocated by the MLDC.

\section{Conclusion}

The MLDC report is profoundly irresponsible. It cavalierly made recommendations that could have devastating effects on the effectiveness of the United States military with only a cursory nod to any of the serious problems that sexual integration would cause and a complete neglect of most of them. When it felt it lacked information on an issue, it did not seek to obtain it; instead, it dismissed concerns as unproven. No policy maker should rely on this report in considering whether to eliminate the exclusion of women from ground-combat arms.

A serious consideration of the central question involved here cannot be made by a "Diversity Commission." Such a commission will always view its charge as primarily about diversity and it will be staffed by people whose expertise (and mission) is diversity. It shows in this report, which does not mention the word "strength" in the context of physical strength, and it does not mention the word "pregnant" or "pregnancy." It uses the word

95 Browne, Co-ed Combat, pp. 268-273. The Commission did acknowledge that its recommendation might affect women's willingness to join the military, but that recognition seems only to have affected its recommendation with respect to timing of implementation. MLDC Report, p. 73.

96

Browne, Co-ed Combat, pp. 148-149, 208-229, 265-268. 
"stakeholder" 15 times but never uses the term to refer to the American people, who, one would think, are the principal stakeholders, with their security being the principal stake. It uses the word "cohesion" only 6 times. The word "battlefield" is not mentioned at all, but the word "diversity" appears over 700 times. One would have to look long and hard to find a more frivolous and irresponsible study.

Battlefield effectiveness should be the sine qua non of manpower policy. The decision whether to alter military manpower policy radically in a way unprecedented in human history should be based on an analysis made by people who know something about the subject, with military effectiveness and not diversity as its guiding principle. 


\begin{abstract}
About the Author
Kingsley Browne is a professor of law at Wayne State University Law School in Detroit.(http://faculty.law.wayne.edu/browne/index.htm) He has written extensively about the subject of women in the military and in combat. His publications on these topics include:

Co-ed Combat: The New Evidence That Women Shouldn't Fight the Nation's Wars (2007), Sentinel (Penguin USA)

"Band of Brothers or Band of Siblings? An Evolutionary Perspective on Sexual Integration of Combat Forces," in Todd K. Shackelford \& Viviana Weekes-Shackelford (eds.), Oxford Handbook of Evolutionary Perspectives on Violence, Homicide, and War, Oxford University Press, pp. 372-392 (part of the Oxford Library of Psychology series) (2012) (in press)

"Sex Differences in the Workplace and the Military," in Yan-jie Su \& X. T. Wang (eds.), Thus Spake Evolutionary Psychologists, pp. 222-231, Peking University Press (2011)

"Sex Differences in Aggression: Origins and Implications for Sexual Integration of Combat Forces," Behavioral and Brain Sciences, 32:270-271 (2009)

"Military Sex Scandals from Tailhook to the Present: The Cure Can Be Worse than the Disease," Duke Journal of Gender Law \& Policy, 14:749-789 (2007)

"Women at War: An Evolutionary Perspective," Buffalo Law Review, 49:51-247 (2001)

"The Relevance of Sex Differences in Risk-Taking to the Military and the Workplace,” Behavioral and Brain Sciences, 22:218-219 (1999)
\end{abstract}

